\title{
O CORPO LGBT PATOLOGIZADO: FRATURAS E DEGRADAÇÕES DO LUGAR DO SER EM UM CENÁRIO DE VIOLÊNCIAS ${ }^{1}$
}

Ana Márcia Ruas de Aquino* Hugo Mari**

RESUMO: Pretende-se, com este texto, questionar o cenário social, político, linguageiro, cultural e histórico, que deve demandar posicionamentos de resistência no que concerne ao preconceito sexual vigente, capaz de rotular, destruir psicologicamente e até mesmo ceifar a vida de outros seres humanos, por razões ligadas a uma racionalidade subjetiva que encontra anuência em um discurso heteronormativo, sexista e homofóbico, ao reproduzir crenças, valores e desejos hetrossexualizados, com corpos rotulados por metáforas estigmatizadoras, nas relações de poder que se reforçam numa sociedade que tem como norma o hétero, descartando o homossexual e praticando ações homofóbicas paroxistas. No intuito de definir-lhe os aspectos atuais mais constantes, busca descrever o cenário da patologização do não heteronormativo e delinear, no contexto da heteronormatividade, a LGBTfobia, com categorias naturalizadas e manipulação de símbolos a essas categorias semânticas como reflexo da cognição humana, pela capacidade humana de categorizar e reproduzir categorias produtoras de sentidos metafóricos sexistas.

PALAVRAS-CHAVE: Corpo LGBT; Heteronormatividade; Homofobia; Patologização.

${ }^{1}$ Recorte de pesquisa de doutoramento em Linguística e Língua Portuguesa do Programa de Pós-Graduação em Letras, pela Pontifícia Universidade Católica de Minas Gerais, com bolsa da Fapemig.

* Professora da Universidade Estadual de Montes Claros (Unimontes). Doutoranda em Linguística e Língua Portuguesa pela Pontifícia Universidade Católica de Minas Gerais (Puc-MG); mestre em Linguística e Língua Portuguesa pela Puc-MG. Bolsista da Fapemig.

** Professor do Programa de Pós-graduação em Letras da Puc-MG. 
[o prazer] escapa às conotações médicas, naturalistas e que carregam junto com elas a noção de sexualidade. Não há, no fim das contas, prazer 'anormal', não há 'patologia' do prazer. (FOUCAULT, 2015, p. 6).

Possuir um traço que o tire da norma, [+ homossexual], [- heterossexual], configura, em nossa sociedade, algo patologizado, [- normal], o que é uma estereotipia que atravessa o ser, em nossa cultura, nessa sociedade calcada no binômio heterossexual e homossexual. Mas, mais que isso, esse traço banaliza a homossexualidade a tal ponto que o LGBT $^{2}$ passa a ser visto com o estigma de quem possui uma doença e, assim, banaliza-se (e matase!) o que se considera patológico. Ou pune-se, segrega-se, mesmo em tempos da tão difundida inclusão social e do dito respeito às diferenças.

Diante desses fatos, iremos discorrer acerca dos paradigmas atuais heteronormativos, que patologizam as homossexualidades, reforçando os estigmas e relegando os LGBTs, muitas vezes, à marginalidade.

São vários os estudiosos que desenvolvem pesquisas sobre sexualidades, identidades de gênero, queerização, sexismo e LGBTfobia, no Brasil e no mundo. Entre os brasileiros, destacamos, por terem sido determinantes para a construção deste ensaio, Felipe e Bello (2009), Furlani (2009), Junqueira (2009), Louro (2001; 2004a; 2004b). Além disso, algumas obras institucionais foram de grande valor para a pesquisa realizada, tais como: Caderno Escola sem Homofobia: Kit de ferramentas educacionais (BRASIL, 2011), estando entre os principais estudiosos de diversidade sexual estrangeiros: Foucault (2015), Butler (2010) e Sedgwick (2007).

Passemos, então, aos paradigmas que se relacionam aos símbolos homossexualizados e heterossexualizados em nossa sociedade, diante da percepção notória de que há mais

${ }^{2}$ Utilizamos a sigla LGBT por ser esta já consolidada pelo uso, em vez da sigla atualmente referida: ALGBTTTIQ (Assexuais, Lésbicas, Gays, Bissexuais, Transgêneros, Transexuais, Travestis, Intersexuais, Queer), embora saibamos da complexidade que envolve essas siglagens, pela performatividade, pois o gênero não é apenas "uma inscrição cultural" (BUTLER, 2010, p. 25) sobre um corpo, um ser. 
do mesmo nos presentes paradigmas, com as incongruências sociais, a estigmatização e a marginalização, estas construídas pela capacidade humana de categorizar:

As mensagens, ainda que encobertas, são bem claras: não ser heterossexual é algo muito ruim, algo que ninguém quer ser e, portanto, serve de xingamento. Trata-se de preconceito, pois não há muito como fugir ao consenso de que, a não ser em situações inusitadas, ninguém é "xingada/o" de "heterossexual". Muitas vezes, no ato de se pronunciar “bicha!”, “sapatão!” ou “traveco!", é a homofobia que se manifesta, reclamando um não respeito aos atributos masculinos ou femininos tidos como "naturais". Nesse caso, o que se denuncia é uma linguagem preconceituosa, que dá a ideia de que há um "gênero correto" ao qual a pessoa referida deveria pertencer "naturalmente". Trata-se de uma forma particular de sexismo, revelando que a homofobia é aprendida, ou seja, também envolve os processos de cognição. Elabora-se cognitivamente o rechaço às pessoas que não se enquadram nas condutas supostamente determinadas para seu sexo biológico. (BRASIL, 2011, p. 64)

Parecem-nos naturais ou antinaturais - sendo essas as duas únicas vias - as coisas que são incorporadas ao nosso cotidiano, porque passam pelo crivo da nossa avaliação como possuindo ou não as suas incongruências, pela normalidade ou anormalidade que, para nós, possam traduzir. O que se concebe como normal - e se torna, por isso, a norma da nossa sociedade - pode deixar camuflados alguns aspectos por nós naturalizados como melhores, socialmente.

Se observarmos com sobriedade (diga-se, sem afetações sociais, culturais, históricas, etc.), veremos que esses aspectos que são por nós naturalizados (como normais ou anormais) são, de fato, fundados em categorias, em relações prototípicas, estabelecidas socioculturalmente.

Para explicitar, de forma um tanto geral, essa questão, podemos fazê-la por meio de ilustrações do que é por nós reproduzido e revela (ou encobre) estigmas sociais que, diariamente, enunciam-se, em contextos diversos: 


\section{(1) O estigma às profissões ou aos profissionais}

(Em falas que dizem estar defendendo a inclusão, quando, de fato, apregoam a exclusão escamoteada, ou seja, inferiorizam uma classe.)

\section{Exemplos:}

(1.a) Eu agradeço não só ao presidente desta empresa, mas a todos os funcionários, passando por todos os escalões, inclusive pelos serviçais.

(Em reuniões de confraternização de funcionários, por exemplo.)

OU:

(1.b) Até um gari merece o nosso respeito.

\section{(2) O estigma aos animais:}

\section{Exemplos:}

(2.a) Nem mesmo um animal deve ser tratado como fizeram com aquele menino.

(Em casos de crianças que são espancadas, por exemplo.)

OU:

(2.b) Ainda bem que foi apenas um animal.

(Quando há, por exemplo, um atropelamento seguido ou não de morte.)

\section{(3) O estigma ao ser humano:}

\section{Exemplos:}

(3.a) Eu te amo, desde que...; Eu só te amo se você for assim...

(O amor condicionado, por exemplo, ao veto ao coming out, pelo dispositivo do armário ${ }^{3}$.)

\footnotetext{
${ }^{3}$ Sobre o dispositivo do armário, ver Sedgwick (2007, p. 19-57).
} 
OU:

(3.b) Eu te aceito, mas...

(A aceitação condicionada ao fato de o outro atender a um padrão social hegemônico.)

Esses estigmas são naturalizados, mas vistos como meras falas, aleatórias, porque passam por nós despercebidos como sendo (porque, na verdade, são!) uma forma de estigmatização, de reforço à desigualdade social. Mesmo que nos pareçam inofensivos - ou por mais que se lhes pareçam - é um preconceito, reiterado por ser uma forma arraigada de categorizar, de naturalizar algo ou alguém como melhor (FIGURA 1), em detrimento de tantos outros, como se exemplifica a seguir:

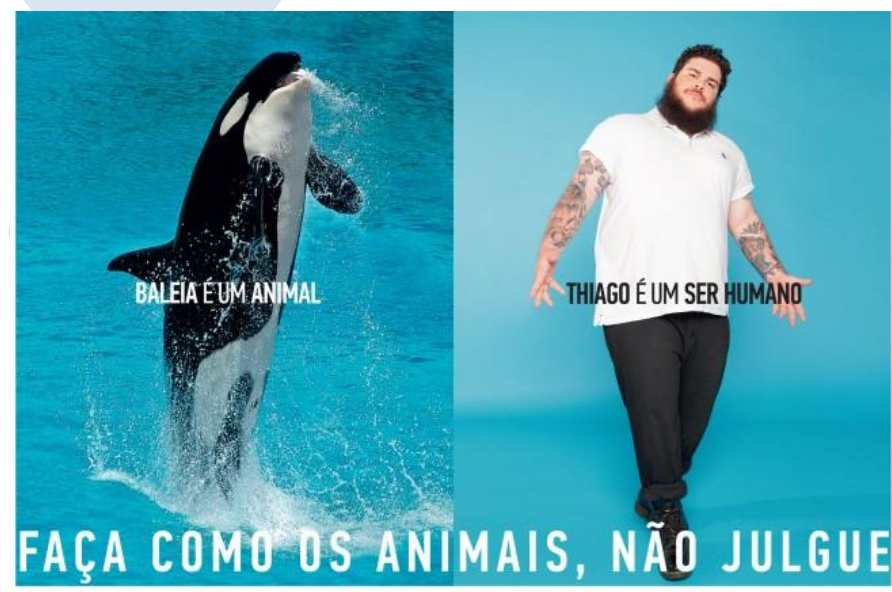

Figura 1: Estigma da obesidade.

Fonte: Mota (2015).

As necessidades de inclusão social "pedem” a desnaturalização dessas categorias, entretanto, embora o século XXI tanto combata a exclusão provocada pelas diferenças de classe social, educação, idade, deficiência, gênero, preconceito social ou preconceitos raciais, etc., não se oferecem oportunidades iguais de acesso a bens e serviços a todos, muito menos o respeito aos direitos humanos. 
E os estereótipos sobre o que deve prevalecer em termos de beleza, de bondade, inteligência, etc., socialmente falando, vão demarcando uma fronteira que cria uma divisão de pessoa para pessoa e entre as coisas.

E, assim, muitos vivem na fronteira: é melhor o corpo que é sarado, independentemente de ser saudável; a escola que "abre" suas portas para alunos com deficiência, para ser inclusiva, mas é excludente ao isolá-los numa sala cheia de colegas "normais", dandolhes como companheiro um profissional para monitorá-los e dividir com eles as atividades; a cultura que culpa a mulher pela atitude do estuprador, imputando a ela o fato de estar seduzindo o indivíduo ao usar, por exemplo, uma minissaia.

Ressaltamos que essas práticas cotidianas são a garantia da reprodução de um modelo que segrega a sociedade, impondo-se um protótipo como superior aos demais, mesmo nas situações mais comuns, sendo preciso observar como os discursos altamente "politizados" são, tantas vezes, contrários às práticas sociais, políticas, educacionais, escolares, familiares, partidárias, vigentes em nosso meio.

Num enfoque às chamadas "minorias"4 silenciadas: negros, índios, pobres, nordestinos, pessoas com deficiência, gordos, refugiados, incluindo-se as "minorias" sexuais: LGBTs, mulheres, torna-se característico resistir, ou pelo menos alavancar um debate contra a opressão, ao serem reproduzidos modelos de preconceito e discriminação, tanto nas falas quanto nas atitudes e nos comportamentos das pessoas.

Em se tratando do comportamento humano, a apropriação do ciberespaço tem sido uma saída com dois extremos: da mesma forma que difunde o respeito às diferenças, tem reproduzido a intolerância ao nosso par, quando este foge ao modelo heteronormativo,

\footnotetext{
${ }^{4}$ Usamos aspas em "minorias" porque, assim como Louro (2001, p. 542), consideramos que essas ditas "minorias" já estão bastante visíveis socialmente: "torna-se mais explícita e acirrada a luta entre elas [as "minorias" silenciadas] e os grupos conservadores. A denominação que lhes é atribuída parece, contudo, bastante imprópria. [...]”, pois "as minorias nunca poderiam se traduzir como uma inferioridade numérica mas sim como maiorias silenciosas que, ao se politizar, convertem o gueto em território e o estigma em orgulho - gay, étnico, de gênero".
} 
quando se encontra na periferia da matriz hegemônica ${ }^{5}$, que é branca, masculina, heterossexual, rica, dita intelectualizada, etc.

Embora vivamos um momento histórico de esgotamento (BRASIL, 2012) e esvaziamento de um modelo de vida, de um paradigma que apresenta sinais de colapso, e que tem passado por rupturas como as dos movimentos, no Brasil, por exemplo, de ocupação de escolas, de jornadas (como as de 2013 e 2015, com protestos e manifestações da sociedade civil no espaço público), ainda assim há um porvir de mudanças que, de fato, extingam com os preconceitos e discriminações raciais, de etnia e de cor, religiosas ou de procedência nacional (já preconizados pela Lei 7.716, de 05 de janeiro de 1989, alterada em 13 de maio de 1997 ) e de que essa lei (QUADRO 1), décadas depois, possa incluir, em seu texto, a homofobia como crime:

${ }^{5}$ Conforme Louro (2004a, p. 17), acerca da matriz heterossexual, hegemônica, tem-se: "Uma matriz heterossexual delimita os padrões a serem seguidos e, ao mesmo tempo, paradoxalmente, fornece a pauta para as transgressões. É em referência a ela que se fazem não apenas os corpos que se conformam às regras de gênero e sexuais, mas também os corpos que as subvertem." 


\section{Presidência da República \\ Casa Civil \\ Subchefia para Assuntos Jurídicos \\ LEI № 9.459, DE 13 DE MAIO DE 1997.}

Altera os arts. 1 으 e 20 da Lei $n$ 은 7.716, de 5 de janeiro de 1989, que define os crimes resultantes de preconceito de raça ou de cor, e acrescenta parágrafo ao art. 140 do Decreto-lei no 2.848 , de 7 de dezembro de 1940.

O PRESIDENTE DA REPÚBLICA Faço saber que o Congresso Nacional decreta e eu sanciono a seguinte Lei:

Art. 1 O Os arts. 1 e e 20 da Lei $\mathrm{n} 07.716$, de 5 de janeiro de 1989, passam a vigorar com a seguinte redação:

"Art. 10 Serão punidos, na forma desta Lei, os crimes resultantes de discriminação ou preconceito de raça, cor, etnia, religião ou procedência nacional."

"Art. 20. Praticar, induzir ou incitar a discriminação ou preconceito de raça, cor, etnia, religião ou procedência nacional.

Quadro 1: Lei que define os crimes resultantes de preconceito de raça ou de cor, religião e procedência nacional.

Fonte: Brasil (1997).

Um novo paradigma seria construído por meio de mudanças radicais no senso comum. Somos familiarizados com esse antigo (mas, ao mesmo tempo, atual) paradigma que apresenta construções baseadas em pressupostos incongruentes e produtores de imposturas graves, ao se reduzir a complexidade dos fenômenos e analisá-los por partes, com ideias parciais e unilaterais, caracterizando um universo de pessoas cartesianas.

O que há de cartesiano nas relações sociais promove a falsa reprodução de ideais de coletividade, quando o poder que emana dos dominadores desvela um aparente coletivo e impregna o nosso imaginário. 
Assim acontece na nossa sociedade brasileira, capitalista, em que há um modelo a ser comercializado em detrimento de outros, o que conduz a mecanismos de empoderamento do branco, do heterossexual, do magro, do habitante do eixo Rio-São Paulo, etc.

Pensando na questão do foco deste trabalho, que é a heteronormatividade, e fazendo um recorte para essa "minoria" silenciada - os LGBTs -, podemos, com esses modelos culturais, refletir acerca dos significados que se produzem, diante do fato de se reconhecer que os significados são um somatório da vida com a cultura (ZLATEV, 2003), o que tem como ilustração, a seguir, frases (TRIGO, 2017) que são ouvidas pelas crianças desde a mais tenra infância e que acabam sendo por elas (ou por todos) reproduzidas:

(4) Isso é muito gay.

(5) Você chuta como uma garota.

(6) Eu não tenho problema algum com gays, só não quero que meus filhos sejam...

(7) O que as lésbicas fazem na cama?

(8) Você é passivona!

(9) Você escolheu ser gay, né?

(10) Eu não tenho problema com gays, só não gosto que eles fiquem se agarrando na minha frente.

(11) Nossa, que desperdício!

Frases como essas são aprendidas cognitivamente, por envolver esse aprendizado os processos de cognição, sendo a homofobia, portanto, aprendida desde o berço e ocasionadora da discriminação de pessoas "que não se enquadram nas condutas supostamente 
determinadas para seu sexo biológico", de acordo com o Caderno Escola sem Homofobia: kit de ferramentas educacionais (BRASIL, 2011, p. 64).

Assim, os LGBTs tornam-se inadequados para essa conduta naturalizada, que é vinculada à heterossexualidade e tomada como natural, normal, "real":

Se aceitarmos também como possível que nossa cultura é heteronormativa, poderemos acreditar que o binômio homo/hetero é pertinente, que ele é "real". Então poderemos dizer que o homossexual é a figura que distingue, define e desenha o que é ser um heterossexual. Vale lembrar que a homossexualidade tem uma história recente, pois ela é dependente da noção de sexualidade que foi constituída na modernidade (FOUCAULT, 1999; WEEKS, 1999). Sua definição surgiu no final do século XIX. Antes disso, ela era entendida como um "vacilo" que todos poderiam cometer, sem que com isso se passasse a ser um outro tipo de pessoa. Seria considerado pecador, sodomita quem usufruísse dessas práticas e, como pecadores, deveriam pagar pelos seus erros (TREVISAN, 2000). Ao se aproximar o final desse século, a heterossexualidade tornou-se norma definidora do possível (ela própria) e do inaceitável (o que dela se afasta). Quanto à heterossexualidade, podemos dizer que esta não tem história; não se encontra um marco que a funde, ela simplesmente é tomada como natural. (FELIPE; BELLO, 2009, p. 146147).

E essa discriminação irrompe em fraturas e degradações do lugar do ser, com a patologização dos corpos LGBTs, degradados em um cenário de violências, pelo binarismo classificatório da realidade brasileira, num binômio masculinidades/feminilidades.

Nesse atual cenário brasileiro (que pode desenrolar-se, também, em nível mundial), a patologização dos LGBTs aponta para um paradigma que deliberadamente não se desconstrói, pelo contrário, realimenta-se de novas formas de preconceito e discriminação, ao se pensar em “cura gay”, ou seja, numa terapia de reorientação sexual ou conversão, a qual compreende o uso de métodos que alterem a orientação sexual homossexual de um indivíduo para a heterossexualidade. 
Embora o preconceito não seja uma especificidade da nossa época, a realidade da cena brasileira tem matado emocional e também fisicamente muitos LGBTs, mesmo em tempos de queerização $0^{6}$, em que se parece difundir essa teoria queer a todos os cantos do mundo, com o aprofundamento de estudos e da defesa das "minorias" sexuais (gays, lésbicas, bissexuais, transgêneros, etc.) e das demais "minorias" sociais.

A queerização, que defende os sujeitos estigmatizados ou considerados ilegítimos, aponta para uma denúncia a processos que heterossexualizam instituições, discursos, direitos. E, em contrapartida, desarticulam processos que negam ou agregam instituições, discursos e direitos, homossexualizando-os.

O dispositivo do poder heteronormativo coloca o ser em constante conflito consigo e com seus pares e, em se tratando da "cura gay", torna-se eficiente um tipo de produção de subjetividade controlado, na direção política que se impõe, submetendo essa "minoria" a um diagnóstico e intervenção de uma doença que diz respeito à conduta, aos transtornos antissociais, aos desvios padrões, de acordo com a heteronormatividade.

É corrente constatarmos ações envolvendo a heterossexualização dos LGBTs, pelos seus "transtornos" de orientação sexual, como o caso do projeto de lei (PL) da "cura gay", ressuscitado (em 2016) pelo deputado Ezequiel Teixeira (PTN-RJ) e reapresentado à Câmara dos Deputados (CIPRIANI, 2017), após ter sido arquivado, e que tem o intuito de permitir que psicólogos e psiquiatras possam trabalhar e intervir para a substituição da orientação de homossexual pela de heterossexual.

Esse PL (4931/2016) visa acabar com a punição ao profissional de saúde que disponibilizar tratamento ao paciente com suposto transtorno de orientação sexual, sendo

\footnotetext{
${ }^{6}$ No Brasil, a primeira publicação acerca da teorização queer voltada para a Educação, em livro único, foi editada em 2004. Trata-se de Um corpo estranho: ensaios sobre sexualidade e teoria queer, de Guacira Lopes Louro, que pode ser considerada a pioneira neste assunto, sobretudo por "institucionalizar" a temática, na Linha de Pesquisa "Educação, Sexualidade e Relações de Gênero”, no Programa de Pós-Graduação em Educação da UFRGS, mostrando como as questões levantadas por essa teorização podem ser consideradas politicamente relevantes para os cursos de formação de educadoras/es. (FURLANI, 2009, p. 311).
} 
afirmado, ainda, em seu texto, que essa medida é necessária em “atenção à dignidade humana" (PL 4931/2016). Sendo assim, tem-se a homossexualidade como uma doença.

Em nome dessa dita doença, matam-se, discriminam-se, oprimem-se, reprimemse, rotulam-se pessoas, com ações que envolvem desde a "cura gay" até os assassinatos, os olhares perversos, a homofobia que degrada o lugar do ser humano, impondo um cenário de fraturas e violências, como se pode observar, a seguir (FIGURA 2):



Figura 2: Faixa homofóbica em Porto Sauípe (BA), afixada em uma igreja evangélica. Fonte: Gauthier (2016).

Aqui, ao se expor faixa incitando o homocídio, estimula-se a violência - num ato que deveria ser considerado crime, que caberia indenização coletiva, por ferir a dignidade da pessoa humana -, pois há um desacordo com os direitos humanos e uma inobservância ao amplo conceito de homofobia, dado pela ABLGT - Associação Brasileira de Lésbicas, Gays, Bissexuais, Travestis e Transexuais (BRAGA, 2012):

Atualmente, o conceito de homofobia não se refere apenas a agressão física ou assassinato contra a população LGBT. Segundo a ABGLT, o conceito é mais amplo: "A homofobia é um conjunto de emoções negativas (tais como aversão, desprezo, ódio, desconfiança, desconforto ou medo), que costumam produzir ou vincular- 
se a preconceitos e mecanismos de discriminação e violência contra pessoas homossexuais, bissexuais e transgêneros (em especial, travestis e transexuais) e, mais genericamente, contra pessoas cuja expressão de gênero não se enquadra nos modelos hegemônicos de masculinidade e feminilidade. A homofobia, portanto, transcende a hostilidade e a violência contra LGBT e associa-se a pensamentos e estruturas hierarquizantes relativas a padrões relacionais e identitários de gênero, a um só tempo sexistas e heteronormativos".

Compreende-se que há uma anuência e uma banalização do preconceito e da discriminação contra as comunidades LGBTs, tanto no dia a dia dos indivíduos, em seu convívio pessoal, quanto nas mídias de um modo geral, promovendo o sexismo e formas mais concretas de violência como a morte dessas "minorias" vitimadas.

As manifestações subjetivas dos LGBTs são estigmatizadas e tomadas como uma disfunção ou distúrbio, sendo, assim, alvos a serem combatidos, antes de serem vistas como manifestações subjetivas dos seres humanos, como o são as manifestações subjetivas de todas as (sub)categorias em que se enquadra o ser humano (como os heterossexuais, por exemplo).

Isso visa, assim como é denotado da concepção da "cura gay”, normalizar comportamentos e formas de existir, fazendo dos LGBTs seres anormais, não deixando espaço algum para o sujeito e sua singularidade e, ao que parece, apontam-se razões para pensarmos que o ser humano teme a configuração social a que pertence, desde que ela fuja à norma. Tais fatos tendem a revelar que a natureza humana - que é linguageira - encerra a violência, a recusa, a barbárie e, também, uma necessidade inconsequente ao controle.

Nesse caso da "cura gay", autoriza-se o debate em torno dos acontecimentos humanos, trazendo à tona resoluções simplistas e repressivas ao que não se destina solucionar. E, desse modo, na realidade que aí se configura, podem-se perceber as consequências danosas e drásticas nos contextos em que a homofobia se faz presente na ordem do dia, pelo suposto mal que se tenta combater.

Há uma medicalização da vida, do ser, numa condenação precoce e recorrente ao não heteronormativo, prevalecendo um mal-estar social inibidor da boa convivência, um 
mal que parece percorrer uma civilização inteira, tornando suas causas complexas, numa sociedade pós-moderna do século XXI, sendo suas consequências violadoras do direito à dignidade humana.

Vale destacar que, nesse contexto homofóbico, funda-se também um contrassenso, pois a conduta que determina essa iniciativa bem pode ser considerada uma discriminação, um preconceito, por ferir, causar comoção, perturbar o andamento e indagar o sistema sociopolítico e cultural.

Levanta-se, então, uma reflexão quanto às nossas autoridades políticas, sociais e educacionais controlarem comportamentos e engendrar novos processos de exclusão; entre esses segmentos, a escola:

Ao longo de sua história, a escola brasileira estruturou-se a partir de pressupostos fortemente tributários de um conjunto dinâmico de valores, normas e crenças responsável por reduzir à figura do "outro" (considerado "estranho", “inferior", "pecador", “doente”, "pervertido", "criminoso" ou "contagioso") todos aqueles e aquelas que não se sintonizassem com o único componente valorizado pela heteronormatividade e pelos arsenais multifariamente a ela ligados centrados no adulto, masculino, branco, heterossexual, burguês, física e mentalmente "normal". (JUNQUEIRA, 2009, p. 14)

Nesse caso, percebe-se como a própria escola é difusora desse arsenal patologizante que coloca o outro (o homossexual) como "estranho", "inferior", "pecador", “doente”, "pervertido”, “criminoso” ou “contagioso”, numa disseminação de crenças e valores virulentos, sendo essa uma instituição na qual deveríamos confiar integralmente como formadora de opiniões e defensora de valores e princípios em prol do bem comum.

O ajuste, então, deve estar nas respostas dos sujeitos, que não devem se contentar em aceitar o lugar de refugados, ao qual parecem predestinados socialmente:

[...] os sujeitos que, por alguma razão ou circunstância, escapam da norma e promovem uma descontinuidade na seqüência sexo/gênero/sexualidade serão tomados como minoria e serão colocados à 
margem das preocupações de um currículo ou de uma educação que se pretenda para a maioria. Paradoxalmente, esses sujeitos marginalizados continuam necessários, pois servem para circunscrever os contornos daqueles que são normais e que, de fato, se constituem nos sujeitos que importam. (LOURO, 2004b, p. 27).

Esses aspectos confirmam o lugar de inserção da homofobia, circunscrita nos discursos que regem as condutas e decisões das instituições sociais, educacionais e políticas, as quais são, supostamente, inibidoras desses (e de outros) desequilíbrios sociais.

Mas a homofobia não é algo que está apenas circulando em meios específicos. A força segregadora da heteronormatividade encapsula a sociedade, que apresenta diariamente ações homofóbicas (GRÁFICO 1):

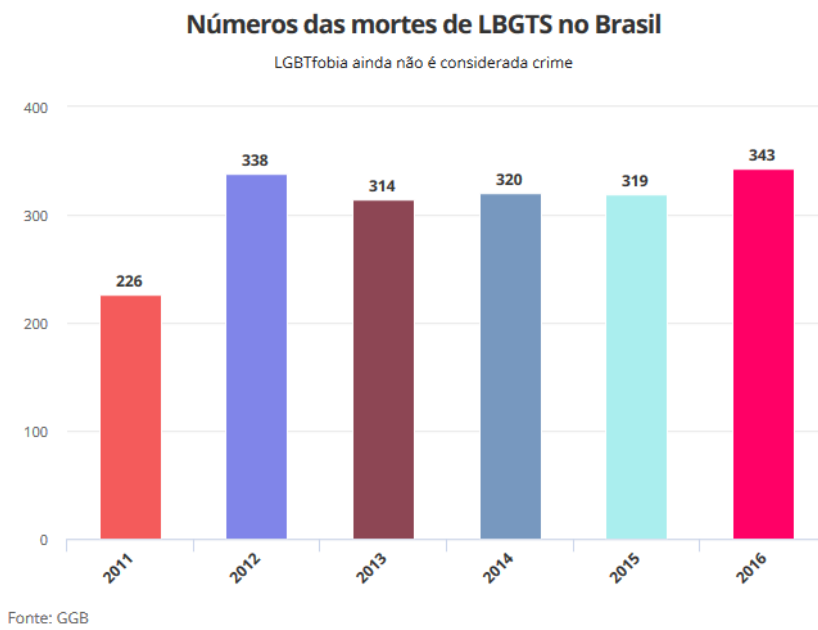

Gráfico 1: Número de LGBTs mortos no Brasil.

Fonte: Oliveira; Jorge (2017).

De acordo com esse gráfico, as mortes homofóbicas, no Brasil, sofreram um elevado crescimento, de 2011 a 2016. 
Esses dados, concluídos no final de 2016, foram reveladores para o ano de 2017, e o Grupo Gay da Bahia (GGB) chamou a atenção para outros números alarmantes e violentos:

Dados divulgados nesta segunda-feira (23) pelo Grupo Gay da Bahia (GGB) mostram que o ano de 2016 foi o mais violento desde 1970 contra pessoas LGBTs. Foram registradas 343 mortes, entre janeiro e dezembro do ano passado. Ou seja, a cada 25 horas um LGBT foi assassinado, o que faz do Brasil o campeão mundial de crimes contra as minorias sexuais. A Bahia ocupa a segunda posição dentre os estados com 32 mortes ficando atrás apenas de São Paulo (49 casos). [...]

Dos 343 assassinatos registrados em 2016, 173 das vítimas eram homens gays (50\%), $144(42 \%)$ trans (travestis e transexuais), 10 lésbicas $(3 \%), 4$ bissexuais (1\%), incluindo na lista também 12 heterossexuais, como os amantes de transexuais (T-lovers), além de parentes ou conhecidos de LGBT que foram assassinados por algum envolvimento com a vítima como foi o caso do vendedor Luís Carlos Ruas, 54 anos, que foi morto ao defender travestis no metrô de São Paulo. (GAUTHIER, 2017, grifos no original).

Apesar desse alto índice de mortes de LGBTs, a LGBTfobia não é considerada crime, como supramencionado neste texto, havendo, por parte de certos grupos políticos e religiosos, razões para se patologizar, segregar e marginalizar os LGBTs.

Isso vem demonstrar a não possibilidade de inclusão das diferenças nesse ambiente hostil, que aponta não para uma diferença de estilo, de opiniões, mas para que se perpetue a existência de corpos transformados - pela homofobia - em corpos-rótulos, que são segregados por essa força dinâmica ideologizante, homocida, que é também etiológica, social, cultural, cognitiva, histórica, política e econômica, engendrada por símbolos que são homossexualizados e heterossexualizados, em nome de um binômio da/na sociedade. 


\title{
THE PATHOLOGIZED LGBT BODY: FRACTURES AND DEGRADATIONS OF THE PLACE OF BEING IN A SCENARIO OF VIOLENCE
}

\begin{abstract}
With this text, it is intended to question the social, political, linguistic, cultural and historical scenario, which must demand positions of resistance regarding the current sexual prejudice, capable of labeling, psychologically destroying and even reaping the lives of other human beings, for reasons linked to a subjective rationality that finds agreement in a heteronormative, sexist and homophobic discourse, in reproducing heterosexual beliefs, values and desires, with bodies labeled by stigmatizing metaphors, in the relations of power that are reinforced in a society that has as its norm the hetero, discarding the homosexual and practicing paroxist homophobic actions. In order to define the most constant current aspects, it seeks to describe the scenario of pathologization of non-heteronormative and delineate, in the context of heteronormativity, LGBTfobia, with naturalized categories and manipulation of symbols to these semantic categories as a reflection of human cognition, by the human capacity to categorize and reproduce categories that produce sexist metaphorical meanings.
\end{abstract}

KEY-WORDS: Heteronormativity; Homophobia; LGBT body; Pathologization.

\section{REFERÊNCIAS}

BRAGA, O. A evolução da homofobia para o homofobismo. Disponível em: http://intoleranciahomossexual.blogspot.com.br/2012/05/, publicado em: 31 maio 2012. Acesso em: 26 maio 2017.

BRASIL. Instituto Brasileiro de Análises Sociais e Econômicas. Grupo Pedras Negras: um debate sobre o futuro das organizações de cidadania ativa. Rio de Janeiro, 2012. Disponível em: http://www.inesc.org.br/noticias/noticias-gerais/2013/janeiro/o-futuro-da-cidadaniaativa-1/at_download/file. Acesso em: 12 set. 2017.

BRASIL. Lei no 9.459, de 13 de maio de 1997. Disponível em: http://www.planalto.gov.br /ccivil_03/leis/L9459.htm. Acesso em: 19 jun. 2017.

BRASIL. Programa de Combate à Violência e à Discriminação. Caderno Escola sem Homofobia: kit de ferramentas educacionais. ECOS - Comunicação em Sexualidade, 2011. Disponível em: https://novaescola.org.br/conteudo/84/conheca-o-kit-gay-vetado-pelo-governo-federal-em-2011, publicado em: 01 fev. 2015. Acesso em: 20 jul. 2017. 
BUTLER, Judith. Problemas de Gênero: feminismo e subversão da identidade. Tradução Renato Aguiar. 3. ed. Rio de Janeiro: Civilização Brasileira, 2010.

CIPRIANI, Juliana. Projeto que libera 'cura gay' está de volta à Câmara dos Deputados. Disponível em: http://www.em.com.br/app/noticia/politica/2017/03/02/interna_politica,851122 /projeto- que-libera-cura-gay-esta-de-volta-a-camara-dos-deputados.shtml, postado em: 02 mar. 2017, às 10h20, atualizado em: 02 mar. 2017, às 10h53. Acesso em: 26 maio 2017.

FELIPE, Jane; BELLO, Alexandre Toaldo. Construção de comportamentos homofóbicos no cotidiano da educação infantil. In: BRASIL. Ministério da Educação. Secretaria de Educação Continuada, Alfabetização e Diversidade. Diversidade sexual na educação: problematizações sobre a homofobia nas escolas. Coleção Educação para todos. Brasília: UNESCO, 2009, 455 p. Disponível em: http://www.dominiopublico.gov.br/pesquisa/DetalheObraForm.do?select_action=\&co_obra=171385. Acesso em: 03 jul. 2017.

FOUCAULT, Michel. "O saber gay”. Trad.: Éder Amaral e Silva e Heliana de Barros Conde Rodrigues. In: Ecopolitica, n. 11, jan./abr. 2015.

FURLANI, Jimena. Direitos Humanos, Direitos Sexuais e Pedagogia Queer: o que essas abordagens têm a dizer à Educação Sexual? In: BRASIL. Ministério da Educação. Secretaria de Educação Continuada, Alfabetização e Diversidade. Diversidade sexual na educação: problematizações sobre a homofobia nas escolas. Coleção Educação para todos. Brasília: UNESCO, 2009, 455 p. Disponível em: http://www.dominiopublico.gov.br/pesquisa/DetalheObraForm.do?select_action=\&co_obra=171385. Acesso em: 03 jul. 2017.

GAUTHIER, Jorge. Igreja evangélica na Babia coloca placa na porta indicando que gays devem morrer: MP apura o caso. Disponível em: http://blogs.correio24horas.com.br/mesalte/igreja-evangelica-na-bahia-coloca-placa-na-porta-indicandoque-gays-devem-morrer-mp-apura-o-caso/, publicado em: 22 jul. 2016. Acesso em: 26 maio 2017.

GAUTHIER, Jorge. Número de mortes de LGBTs bate recorde em 2016 no Brasil; Bahia teve 32 homicídios. Publicado em: 23 jan. 2017. Disponível em: http://blogs.correio24horas.com.br/mesalte/numero-de-mortes-de-lgbts-bate-recorde-em-2016-bahia-teve-32-homicidios/ . Acesso em: 30 jun. 2017.

JUNQUEIRA, Rogério Diniz. Homofobia nas Escolas: um problema de todos. In: BRASIL. Ministério da Educação. Secretaria de Educação Continuada, Alfabetização e Diversidade. Diversidade sexual na educação: problematizações sobre a homofobia nas escolas. Coleção Educação para todos. Brasília: UNESCO, 2009, 455 p. Disponível em: 
http://www.dominiopublico.gov.br/pesquisa/DetalheObraForm.do?select_action=\&co _ o bra $=1713$ 85. Acesso em: 03 jul. 2017.

LOURO, Guacira Lopes. Os estudos feministas, os estudos gays e lésbicos e a teoria queer como políticas de conhecimento. In: LOPES, Denilson et al. (Orgs.). Imagem e diversidade sexual. São Paulo: Nojosa, 2004b.

LOURO, Guacira Lopes. Teoria queer: uma política pós-identitária para a educação. In: Estudos feministas, 2/2001, ano 9, p. 541-553. Disponível em: www.scielo.br/pdf/ref/ v9n2/8639.pdf. Acesso em: 16 jul. 2017.

LOURO, Guacira Lopes. Um corpo estranho: ensaios sobre sexualidade e teoria queer. Belo

MOTA, Gabriel. Reserva lança campanha: "Faça como os animais, não julgue". Disponível em: https://www.agambiarra.com/reserva-faca-como-os-animaisnao-julgue/ . Publicado em: 27 mar. 2015. Acesso em: 15 jul. 2017.

OLIVEIRA, Gleison; JORGE, Thaís. Basta de homofobia: relatos de gay, lésbica, bi, trans e travesti no esporte. GloboEsporte.com, Fortaleza, CE. Publicado em: 19 jun. 2017, às 12h32. Atualizado em: 19 jun. 2017, às 18h58. Disponível em:

http://globoesporte.globo.com/ce/noticia/basta-de-homofobia-relatos-de-gay-lesbicabi-trans-e-travesti-no-esporte.ghtml . Acesso em: 30 jun. 2017.

SEDGWICK, Eve Kosofsky. A epistemologia do armário. Cadernos Pagu, Campinas, no 28, 2007, p. 19-57.

TRIGO, Antonio. Meça sua língua. Disponível em: www.universoaa.com.br/opiniao/8-frases-homofobicas-que-escutamos-por-ai-mas-basta/ . Publicado em: 18 maio 2017. Acesso em: 26 maio 2017, às 20h48.

ZLATEV, Jordan. Meaning = Life (+ Culture): An outline of a unified biocultural theory of meaning. Evolution of Communication, 4/2, 2003, p. 253-296.

Recebido em: 29/09/2017. Aprovado em: 13/11/2017. 